\title{
The emergence of leadership in students' group interaction in a school-based makerspace
}

\author{
Jasmiina Leskinen $^{1}$ (D) $\cdot$ Kristiina Kumpulainen $^{1}$ (D) Anu Kajamaa ${ }^{1}$ (D) $\cdot$ Antti Rajala ${ }^{1}$
}

Received: 14 June 2019 /Revised: 18 August 2020 / Accepted: 21 September 2020 /

Published online: 8 October 2020

(C) The Author(s) 2020

\begin{abstract}
This case study is an examination of the emergence of leadership in students' group interaction in a school-based makerspace. The data comprised video records of 20 primary school students' group work within this context, encompassing student-driven creative engagement in science, technology, engineering, arts, and mathematics (STEAM) learning activities. Interaction analysis was applied to analyze the students' leadership moves and to depict how students' leadership was related to their collaboration. The analysis resulted in a typology of students' leadership moves in a makerspace context, namely, coordination of joint work, exploring new ideas, seeking out resources, and offering guidance and supporting others, adding to the existing literature on student leadership and collaboration in novel learning environments. The study also illustrates how the students' leadership moves in group interactions can lead to dominating and/or shared leadership, with consequences for students' collaboration. The study points to the importance of more research and development of pedagogical practices that support students' symmetric participation and opportunities to lead collaborative work and to promote advanced collaboration in school-based makerspaces.
\end{abstract}

Keywords Leadership · Leadership move · Group interaction · Collaboration · School-based makerspace

\section{Introduction}

Due to changes in society and the learning requirements these pose, there is an increased interest in education to develop participatory student-centered learning environments which are interest-driven and foster students' creative and personal ways of engaging in various STEAM (science, technology, engineering, arts and mathematics) design and making activities

Jasmiina Leskinen

jasmiina.leskinen@helsinki.fi

1 Faculty of Educational Sciences, University of Helsinki, P.O. Box 9, Siltavuorenpenger 5 A, 00014 Helsinki, Finland 
(e.g., Kumpulainen et al. 2019a; Dougherty 2016; Martin \& Dixon 2016; Peppler et al. 2016). Such learning environments, also called makerspaces, include various learning activities such as exploring and questioning, tinkering, testing and iterating, seeking out resources, hacking, combining, complexifying, customizing, and sharing (Brahms and Crowley 2016). A key component of this so-called "maker" approach to STEAM education and learning is not only “do-it-yourself" but also "do-it-with-others" (Peppler et al. 2016). Furthermore, Peppler et al. (2016) describe makerspaces as communities of practice, in which more expert makers serve as models and mentors for newcomers while the newcomers bring their personal ideas into a joint making process (Peppler et al. 2016).

Collaboration is considered to be essential in makerspaces as it gives youth a substantial say in what and how they design and make, leaving it to students to determine where the activity is focused and how the group work is conducted (Dixon and Martin 2014; Martin 2015; Peppler et al. 2016). A central aspect of collaboration in makerspaces is students' collaboration around the creation of joint artifacts. Previous research on students' creative collaboration in nonmakerspace settings show that students co-construct knowledge and understanding, create new understandings and ways of thinking (Miell and Littleton 2004; Rojas-Drummond et al. 2014, 2008). Moreover, in creative tasks students need to coordinate their work, make joint decisions to construct and modify solutions, and support each other's work through dialog and action (Hennessy and Murphy 1999; Howe and Zachariou 2019).

Given the creative, collaborative, and student-centered nature of makerspaces, they are likely to foster students' initiatives and leadership in organizing their activities and managing their mutual relationships (see, e.g., Martin 2015). However, surprisingly little attention has been directed towards investigating how students' leadership emerges in makerspaces and how it relates to students' collaboration. Yet, leadership is critical for successful performance of collaborative groups (Li et al. 2007; Yamaguchi 2001), as it can promote the consideration of multiple perspectives, efficient organization of group processes, equal opportunities for everyone's participation ( $\mathrm{Li}$ et al. 2007; Mercier et al. 2014), as well as knowledge sharing and achieving common ground during group work (Sun et al. 2017).

With this study, we aim to examine how leadership emerges in students' group interactions, in a novel, digitally enhanced, school-based makerspace, and how students' leadership relates to their collaboration. The contribution of our study is twofold. First, our in-depth analysis of leadership in students' group interactions offers a typology of students' leadership moves in a makerspace context. Second, we generate new knowledge about how leadership is related to students' collaboration in a school-based makerspace. More specifically, our study adds to existing research on collaboration by illustrating how socially constructed modes of dominating and/or shared leadership promoted and/or hindered students' collaboration in the makerspace environment, respectively.

For this study, we defined leadership as an interactional, socially situated process, which emerges and evolves during students' collaboration. Individual students' leadership moves have a contributory role in this process (e.g., Gronn, 2000; Kantor et al. 1993; Mawson 2011), and we define leadership moves as students' active attempts to influence group work with consequences to their collaboration ( $\mathrm{Li}$ et al. 2007). Drawing on sociocultural theories of collaboration, for our study we define collaboration to encompass co-construction of knowledge and meanings, which occurs when students engage in the collective activities and practices mediated by tools and signs (Miell and Littleton 2004; Rojas-Drummond et al. 2008). Further, we consider students' collaboration to involve "purposeful forms of 
engagement among peers" (Christie et al. 2009), and see it as emerging in a particular institutional and cultural context (Rojas-Drummond et al. 2008).

To these ends, in this study we ask:

1. What leadership moves emerge in students' group interactions in the makerspace?

2. How is students' leadership related to their collaboration?

\section{Leadership in students' group interactions}

There is a long tradition of leadership research among adults in organizational contexts (e.g., Chemers 2000). During the past two decades, increased research attention has also been directed towards studying leadership in groups of primary and secondary school students (Buchholz et al. 2014; Mercier et al. 2014; Miller et al. 2013; Richmond and Stirley 1996; Sun et al. 2017; Yamaguchi 2001) and even among young children in early childhood settings (Mawson 2011; Mullarkey et al. 2005; Lee et al. 2005). Previous research has investigated student leadership during mathematical problem-solving (Yamaguchi 2001; Mercier et al. 2014), collaborative reasoning discussions ( $\mathrm{Li}$ et al. 2007; Sun et al. 2017), and educational online environments (Siewiorek et al. 2012). However, this body of research has mainly focused on structured collaborative activities in which the problem to be solved and the group composition were defined by the teachers or researchers from the outset. In contrast to these studies, Buchholz et al.'s (2014) study showed how middle school youth leadership emerged in a creative and open-ended workshop involving making and designing e-textiles. Further, in Buchholz et al.'s study (2014), the making and design activities around e-textiles were found to transform gender roles by providing the girls with opportunities to participate in the study to take leadership in highly technical and typically male-dominated STEM areas.

The existing body of research suggests that leadership is a complex and emergent process (Li et al. 2007; Mercier et al. 2014; Siewiorek et al. 2012; Sun et al. 2017). The emergent process of leadership is developed through interactions between members of a group (Miller et al. 2013; Richmond and Stirley 1996; Yamaguchi 2001), and leadership is viewed as a relational rather than an individual construct (Shin et al. 2004). According to the literature, leadership is evidenced through leadership moves that initiate activities, assign roles, and generally control the direction and manage the routines of group activities (Kantor et al. 1993; Mawson 2011). Leadership can also show itself in interaction that reflects high awareness of the activity as well as a sense of ownership of the activity (Shin et al. 2004). Any student can attempt to take the lead in a collaborative activity (e.g., Li et al. 2007). However, the legitimacy of a student's role as a leader depends on whether the other group members follow the attempts to lead, thus making leadership a reciprocal process (Li et al. 2007; Mercier et al. 2014; Sun et al. 2017). Furthermore, a study by Volet et al. (2017) demonstrated that students' flexibility in alternating between the roles of leaders and followers, advances group collaboration, as well as its productivity; the more flexible the shifts between the roles of the leaders and their followers, the more advanced the collaboration and the productivity of the group (Volet et al. 2017).

Yamaguchi (2001) also suggests that students' orientations towards joint activities shape the nature of leadership. For instance, competitive orientations in joint work can build leader dominance and relational issues. According to Buchholz et al. (2014), such leadership can manifest itself in interactions that ignore other group members, reject others' ideas, uphold 
physical control over the task and the equipment used, and in turn, compromise or even threaten collaboration (Buchholz et al. 2014; see also Yamaguchi 2001). On the other hand, an orientation towards learning new skills in collaboration with others can advance democratic leadership and student engagement in a collaborative activity (Yamaguchi 2001). In turn, productive collaboration can be promoted by making leadership moves, which carry an inclusive tone, respectful attitude towards others, and open-mindedness to alternative perspectives (Sun et al. 2017).

Li et al. (2007) investigated students' leadership by analyzing leadership moves enacted during collaborative reasoning discussions of small groups and found moves that managed turn taking, developed arguments, planned and organized the work, and controlled the topic of discussion. In addition to these categories, Mercier et al. (2014) found moves that supported the achievement of a group's goals by introducing new ideas during joint work and which drove the group forward intellectually. Moreover, Sun et al. (2017) adapted the leadership categories developed in the study by Li et al. (2007) to fit a mathematical task. The leadership moves found in Sun et al.'s (2017) study include allocating tasks, proposing and justifying solutions, planning and organizing, and seeking consensus. Further, earlier research on leadership moves indicated that planning, organizing, and seeking consensus promote coordination during collaboration and can lead to equal participation among group members (Li et al. 2007; Sun et al. 2017). It also demonstrates that leadership moves that introduce new ideas and develop arguments enhance the productivity of collaborative groups (Li et al. 2007; Mercier et al. 2014; Sun et al. 2017).

In this study, we stress the socially situated nature of leadership (Gronn 2000; Kantor et al. 1993; Mawson 2011) and define leadership as a social process in which leadership moves of individual students have a contributory role (Gronn 2000). This process contributes to the structuring of students' work (Gronn 2000), driving the direction, and managing collaborative activity (Kantor et al. 1993; Mawson 2011). Following Li et al. (2007), we use the concept "leadership moves" as an analytical unit to capture such socially situated processes of leadership. We define leadership moves as students' active attempts to influence group work (Li et al. 2007; Mercier et al. 2014; Sun et al. 2017). Further, we view leadership moves as active attempts in the sense that they are bids to take responsibility and initiative over the group work ( $\mathrm{Li}$ et al. 2007) and aimed at influencing group work through determining the tasks and roles of others and managing the general direction of the group activity (Mawson 2011). Moreover, we define a leader as a student who makes leadership move/s (Li et al. 2007; Mercier et al. 2014; Sun et al. 2017) and whose role as a leader is legitimized in the other students' interactions that follow the leadership move/s (Li et al. 2007).

\section{Methods}

\section{Research context}

Our study was undertaken in a Finnish, city-run comprehensive school, which had recently undergone a curriculum reform focused on the development of the students' digital and learning-to-learn skills, and whose formal classroom learning environments were extended by introducing a new school-based makerspace, the FUSE Studio (Stevens et al. 2016). The school has 535 students and 28 teachers at the primary level. The school offers FUSE as an elective subject to students in grades four to six. 
The FUSE Studio ${ }^{1}$ provides students with open-ended STEAM projects, called "challenges." The FUSE Studio follows design principles, namely, a digital game-like environment with challenge levels of increasing difficulty like in video games, student choice in selecting the challenges to work on as well as with whom to work, a clear connection to particular STEAM fields in industry, and minimal formal assessment (Stevens and Jona 2017). The assessment of a student's participation and learning does not include grading but is carried out by utilizing photos, video, or other digital artifacts and the student's own documentation. The challenges students engage in range from designing jewelry or a "dream home" with 3D modeling software to making windmills, solar-powered cars, laser mazes, and roller coasters. Some of the challenges are fully digital and in some, students use physical materials that are provided to them in separate kits. The students can access the challenges and their instructions through a website (Fig. 1). Figure 1 demonstrates the students' view of the digital FUSE Studio environment, on which the students find trailer videos of each FUSE challenge and choose the challenge most appealing to them based on these trailers. On the website, students can access the challenge instructions, which include both written instructions and video tutorials. During data collection, the students can use the school's computer laboratory, one regular classroom, and the corridor. Students can choose which challenges they wanted to work on as well as where and with whom to collaborate. Further, the students do not have to rely on their teachers' interpretations of the challenge instructions - or interpretations of what the final product will look like - but can have an active role with opportunities and responsibilities to construct meaning, make judgments, and interact with peers to broaden interpretations and direction of joint work (see also Certo 2011). Thus, FUSE provides students with a substantial say in how they engage in the design and making activities.

\section{Data sources}

The data sources included $85 \mathrm{~h}$ of video records, which we collected by filming the students $(N=$ $94)$ and teachers $(N=7)$ in the FUSE Studio ${ }^{2}$. We collected data three times a week from August to December 2016. The data were taken from three groups of students who had chosen the FUSE Studio as an elective course for the 2016-2017 academic year; Group 1 consisted of 32 4th graders ( 22 boys and 10 girls), Group 2 of 30 5th graders (19 boys and 11 girls), and Group 3 of 32 6th graders (19 boys and 13 girls). Each group had one 60-min FUSE session a week. Each group had two appointed teachers to support the students' work in the FUSE Studio. We used four video cameras to capture the activities of students and teachers. Usually two of the cameras followed the teachers and two were set to record selected students' work. The main principle that guided the decisions regarding the focus of the cameras for each session was the need to form a comprehensive picture of the nature of interaction and activities in the FUSE Studio.

During data collection, we produced an Excel spreadsheet with overall descriptions of the design and making activities across the $85 \mathrm{~h}$ of video data. This spreadsheet included the identification of students and teachers and the names of the FUSE challenges. Based on the spreadsheet, we selected a data set for in-depth analysis. To answer our research questions, that is, to analyze the students' interaction and leadership moves in these, as well as the nature of their collaboration evolving across group work, we selected parts from the videos that met the

\footnotetext{
${ }^{1}$ The FUSE Studio website can be viewed from: www.fusestudio.net

${ }^{2}$ The study followed the ethical standards laid out by the Finnish National Board on Research Integrity. The research respects the teachers' and children's anonymity and privacy, and all names mentioned in this paper are pseudonyms.
} 


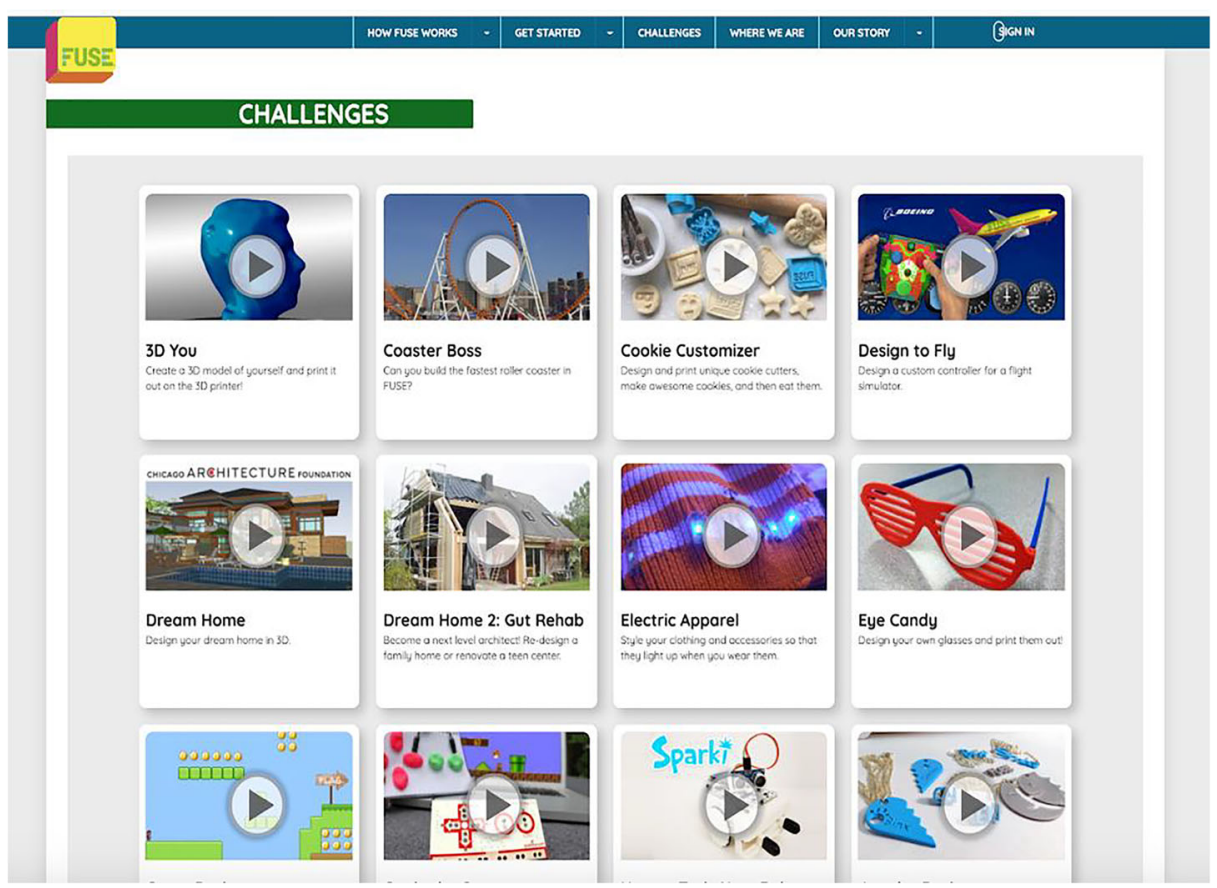

Fig. 1 FUSE Studio view for the student

following criteria: (1) the videos displayed groups of students who chose to work on challenges in which they collaborated to design and make a shared artifact, and (2) the videos displayed students who chose to work in the same group for an entire 60-min FUSE Studio session. We found five small groups from the video data who met these criteria. The video data subjected to in-depth analysis amounted to 5 hours in total. Each small group had four students, with one group consisting of 4th graders (age 9-10), three of 5th graders (age 1011 ), and one of 6th graders (age 11-12). On each of the videos, we had one camera that was set to film the group. The angle was adjusted according to the students' movement in the space.

\section{Data analysis}

In order to detect leadership moves from the students' interactions, and to analyze how leadership was related to the students' collaboration, we produced detailed transcriptions of each of the five selected videos. First, we imported the selected videos and their transcriptions into the MAXQDA ${ }^{3}$ program for systematic analysis. We then applied the techniques of interaction analysis (Jordan and Henderson 1995) to analyze the students' verbal interactions, movements in space, gestures, and manipulations of physical FUSE objects. Corrections to the transcriptions were made by reviewing the videos several times during the transcribing process.

To respond to our first research question concerning the identification of the types of leadership move, we conducted an in-depth qualitative analysis of the students' group interaction. Our analytic

\footnotetext{
${ }^{3}$ The MAXQDA is a software package for qualitative and mixed methods research. More information on the program can be retrieved from: https://www.maxqda.com/
} 
approach can be defined as abductive, as the analyzing process involved repeated iterations between theory and data (Timmermans and Tavory 2012). We first reviewed the transcriptions turn by turn, to detect leadership moves in the students' interaction. This initial coding was guided by the conceptualizations of leadership moves in earlier leadership research. Thus, an interactional turn was coded as a leadership move when it clearly aimed to influence the group's activity, namely, through organizing the group work and defining the way the work was to be done ( $\mathrm{Li}$ et al. 2007). We then used Li et al.'s (2007) coding scheme of leadership moves, which includes the following leadership moves: turn management, argument development, planning and organizing, topic control, and acknowledgement. However, we felt it was necessary to label the leadership moves in a way that the labels illustrate the moves' functions (see also Mercier et al. 2014; Sun et al. 2017) in the makerspace context. The coding scheme was thus modified through an iterative process (see Srivastava and Hopwood 2009), which led to the following typology of students' leadership moves in a makerspace context: coordination of tasks, exploring new ideas, seeking out resources, and offering guidance and support to others.

The MAXQDA program produced a quantitative overview of how frequently the different types of leadership move occurred in our data. The codes used, their frequencies, and illustrations of leadership moves in each type are shown in Table 1 in the "Results" section. The numbers in the quantifications represent preliminary indications of different types of leadership move in this particular research setting and are not a quantitative analysis of any representative sample as such. The quantifications were used to support our interpretations in the "Results," "Discussion," and "Conclusions" sections.

To answer our second research question on how students' leadership is related to their collaboration, we first counted the leadership moves used by each student, as well as how many of these led to the student's role as a legitimized leader (i.e., whose leadership move was followed rather than rejected by the other students). As equal opportunities for participation and flexibility in alternating between the roles of leaders and followers have been found to advance collaboration ( $\mathrm{Li}$ et al. 2007; Mercier et al. 2014; Volet et al. 2017), for a deeper analysis, we chose two student groups that had a noticeable difference in how symmetrically individual students made leadership moves and how these led to a role of a leader. In the first group, the frequency of leadership moves between the four students was uneven, and importantly, only one student's leadership moves were in general followed by other students. In the second group, all four students performed leadership moves relatively evenly, and they all had opportunities to lead joint work; their moves were equally followed by group members. We then analyzed how the students' leadership moves contributed to the social process of leadership within the two groups to capture how leadership was related to the nature of their collaboration.

We have provided detailed empirical illustrations from the students' interaction in these two groups in the "Results" section. These illustrations exemplify the students' leadership moves and their relation to the students' collaboration.

\section{Results}

\section{The types of leadership move}

Our findings make visible four types of leadership move in the students' group interactions, namely, coordinating joint work, exploring new ideas, seeking out resources, and giving guidance and support to other group members. Table 1 shows the four types of leadership move and their 
Table 1 Types of leadership move in collaborative design and making

\begin{tabular}{|c|c|c|c|}
\hline Row & Leadership move & Example & Occurrence \\
\hline 1 & $\begin{array}{l}\text { Coordinating joint work: } \\
\text { Organizing the working process, } \\
\text { managing the activity, assigning } \\
\text { tasks within the group }\end{array}$ & $\begin{array}{l}\text { "Silja, you can wave the green flag like this. } \\
\text { Riina, you can wave the checkered flag like } \\
\text { this. I will carry the light and Peppi will film" } \\
\text { (Group 4) }\end{array}$ & $\begin{array}{l}143 \\
(42.4 \%)\end{array}$ \\
\hline 2 & & $\begin{array}{l}\text { "Could you go find us a marble?" } \\
\text { (Group 3) }\end{array}$ & \\
\hline 3 & & "I will look at the instructions" (Group 2) & \\
\hline 4 & & $\begin{array}{l}\text { "Elsa takes the laser pointer from Teemu's hand } \\
\text { and continues to adjust it" (Group 5) }\end{array}$ & \\
\hline 5 & & $\begin{array}{l}\text { "Now we'll test it. If it does not work we'll adjust } \\
\text { that more" (Group 1) }\end{array}$ & \\
\hline 6 & $\begin{array}{l}\text { Exploring new ideas: } \\
\text { Initiatives to change or manipulate } \\
\text { materials and/or change the design } \\
\text { of the artifact }\end{array}$ & $\begin{array}{l}\text { "Why do not we take the smallest blades and put } \\
\text { them between the big ones" (Group 1) }\end{array}$ & $\begin{array}{c}84 \\
(24.9 \%)\end{array}$ \\
\hline 7 & & $\begin{array}{l}\text { "You need to make the loop a lot smaller, so that } \\
\text { it gets speed" (Group 2) }\end{array}$ & \\
\hline 8 & & "Wait. Let us twist the blades a little." (Group 1) & \\
\hline 9 & $\begin{array}{l}\text { Seeking out resources: } \\
\text { Using written instructions/video } \\
\text { tutorials, seeking help from teachers } \\
\text { or peers }\end{array}$ & $\begin{array}{l}\text { "The guy on the video says that if it (the car) } \\
\text { moves backwards, try to switch the wires, so } \\
\text { that this (wire) goes here." (Group 4) }\end{array}$ & $23(6.8 \%)$ \\
\hline 10 & & "Hmm... well... go and ask the teacher" (Group & \\
\hline 11 & & $\begin{array}{l}\text { (Benjamin looks at a group working next to them, } \\
\text { and then turns back to Aaro,): "You need to } \\
\text { put that there" (Group 1) }\end{array}$ & \\
\hline 12 & $\begin{array}{l}\text { Offering guidance and support to other } \\
\text { group members: } \\
\text { Support in finding instructions, in } \\
\text { construction of the artifact, in } \\
\text { problem-solving }\end{array}$ & $\begin{array}{l}\text { Aaro shows Daniel where to find instructions on } \\
\text { the FUSE Studio website (Group 1) }\end{array}$ & $87(25.8 \%)$ \\
\hline 13 & & $\begin{array}{l}\text { "Max, make the take-off ramp right over there" } \\
\text { (Group 3) }\end{array}$ & \\
\hline \multirow[t]{2}{*}{14} & & $\begin{array}{l}\text { "If the car moves like this (on two wheels), so if it } \\
\text { is like this (on four wheels), how do you turn } \\
\text { the light then?" (Group 4) }\end{array}$ & \\
\hline & & & $337(100 \%)$ \\
\hline
\end{tabular}

percentages of occurrence relative to the total frequency of leadership moves. The numbers in the first column represent row numbers referred to later in the "Results" section in which we make interpretations related to the leadership moves we found. The second column points out the names of the types of leadership move found in this study, each of which represents the particular function they served in the group's work. The empirical examples in the third column illustrate the function of each type of leadership move. The fourth column presents the percentage of occurrence of each type of leadership move. Next, we elaborate on these examples and illuminate how the students used the four types of leadership move during their joint design and making activity.

\section{Coordinating joint work}

The results show how engaging in the makerspace was very much about the students coordinating their joint work (42.4\% of detected leadership moves, see Table 1). Coordinating 
joint work was characterized by the students taking over the group activity by organizing the working process, managing the activity, and/or assigning tasks within the group. These leadership moves also included telling other students in the group what to do (Table 1, row 1), asking someone to take up a task (Table 1, row 2), telling others about a task they were about to take on (Table 1, row 3), and gaining physical control over the materials used in the FUSE challenge (Table 1, row 4) and managing the conduct of activity (Table 1, row 5). Thus, coordination of joint work entailed the students' promoting everyone's participation in group work (Table 1, rows 1, $2 \& 4$ ), ensuring that all necessary tasks were attended to (Table 1, rows $1 \& 3$ ), coordinating and controlling the use of tools and materials (Table 1, row 4), and coordinating the processes of the design and making activity (Table 1, row 5).

\section{Exploring new ideas}

Exploring new ideas covered $24.9 \%$ of all the identified leadership moves. These interactional moves included initiations for changing the materials used in the design and making activity (Table 1, row 6), suggestions for changing the design of the artifact (Table 1, row 7), and explorations to adjust the materials to better fit their needs (Table 1, row 8). The examples given in Table 1 illustrate envisioning new opportunities afforded by the materials used in the challenges (Table 1, row 6), critical reflections on related STEAM concepts, such as speed, to meet the objectives of the FUSE challenge (Table 1, row 7), as well as envisioning new opportunities for the design of the artifact the students were making (Table 1, row 8).

\section{Seeking out resources}

These leadership moves covered $6.8 \%$ of the identified leadership moves. These moves were particularly related to situations in which the students needed external support in developing the artifact related to the FUSE challenge in question. In most cases, the students followed the written instructions or the tutorial videos on the FUSE website (Table 1, row 9). However, in some cases, the students used the teacher as a resource (Table 1, row 10), or observed their peers working on the same challenge and then used these observations to guide their design and making activity (Table 1, row 11).

\section{Offering guidance and support to other group members}

These interactions formed $25.8 \%$ of all the detected leadership moves (see Table 1). Offering guidance and support was related to helping other students in finding instructions on the FUSE website (Table 1, row 12), giving guidance on how to manipulate the materials used in the challenge (Table 1, row 13), and providing support for changing the design of the artifact (Table 1, row 14). These examples illustrate how giving guidance and support promoted the participation of each group member in the joint design and making activity.

\section{The social process of leadership and the nature of the students' collaboration}

Next, we discuss our findings with regard to our second research question, that is, how the students' interactionally constructed leadership was related to their collaboration. Here, we provide detailed descriptions of the interaction in two small groups. 


\section{Dominant leadership}

First, we examined a group of four students (Group 1, Table 2), Emma, Heini, Iida, and Jenni, who worked on the Coaster Boss challenge to design and construct a roller coaster for a small marble. The materials kit included foam rubber, tape, scissors, a marble, a tape measure, and a speedometer. The most leadership moves in this group belonged to Emma (52.6\%). By contrast, the three other students in this group, Heini, Iida, and Jenni, performed much smaller fractions of all the leadership moves (Heini 28.1\%, Iida 14.0\% and Jenni 5.3\%). Emma's leadership moves were also followed the most, covering $90.0 \%$ of her leadership moves. In contrast, only $62.5 \%$ of Heini's, $25.0 \%$ of Iida's, and $33.3 \%$ of Jenni's leadership moves were followed. Hence, Emma's leadership moves more frequently resulted in her position as a legitimized leader in the group work, while Heini, Iida, and Jenni had limited opportunities to emerge as leaders in the joint work. In addition, Emma seemed to execute a dominant mode of leadership in the group's work through ignoring and rejecting others. This dominant leadership was associated with relational issues, such as quarrels, and hindered the development of the roller coaster the students were making and the group did not finish the FUSE challenge of their choice.

The following excerpt is a typical example of the way Emma led the joint work through managing the group process. In this excerpt, the students had taped a piece of foam rubber to the wall and had two loose pieces on the floor:

44. Emma: Alright, Heini, tape this (gives a loose piece of foam rubber to Heini who is holding the foam rubber piece taped to the wall). You tape that and I'll look for - this (another piece of foam rubber). We'll tape these two (loose pieces) together.

45. Emma: No wait, the other way around (Emma takes the loose piece of foam rubber from Heini's hand and turns the piece the other way around). This one - here. Iida help me.

46. Heini: I can tape it (Heini is about to start taping the new pieces to the one taped to the wall)

47. Emma: No, you tape these first (the new pieces together)

48. Iida: Emma what should I tape now?

49. Emma: Those two

In this excerpt, Emma managed group work with leadership moves with which she coordinated the joint work (Turns 44, 45, 47) and offered guidance and support (Turn 45). In turn 44, she assigned the task of taping pieces of foam rubber to Heini. Further, she reinforced her role as a leader by guiding Heini in how the pieces are taped together in turn 45. Further, instead of letting Heini tape the pieces together, she took the piece of foam rubber from Heini's hand and assigned the task to Iida. Emma again reinforced her position as the leader by assigning Heini a

Table 2 Leadership moves in Group 1

\begin{tabular}{lllll}
\hline & Emma & Heini & Iida & Jenni \\
\hline $\begin{array}{l}\text { Leadership moves } \\
\begin{array}{l}\text { Leadership moves resulting in a role of leader } \\
\text { (i.e., followed moves) }\end{array}\end{array}$ & $30(52.6 \%)$ & $16(28.1 \%)$ & $8(14.0 \%)$ & $3(5.3 \%)$ \\
$\begin{array}{l}\text { Leadership moves not resulting in a role of } \\
\text { eader (i.e., rejected moves) }\end{array}$ & $3(10.0 \%)$ & $6(37.5 \%)$ & $6(75.0 \%)$ & $2(66.7 \%)$ \\
\hline
\end{tabular}


new task in turn 47, even though Heini offered to tape the pieces together in turn 46. Iida reinforced Emma's position as the leader by asking her what to tape in turn 48. Overall, the students' interaction began to construct a dominant mode of leadership. This was constructed, namely, in Emma's dominant way of assigning tasks, in Emma's control over how the tasks were performed (e.g., how pieces of foam rubber are taped together), and in other students' responses to Emma's interactions, such as Iida's, when she legitimated Emma's role as a leader by asking her what to do in turn 48. The dominant mode of leadership constructed in the students' interaction legitimated Emma's position as a single leader and as being responsible for managing the conduct of activity. In addition, the dominant mode of leadership resulted in Heini's limited opportunities to participate in joint work.

The next example depicts problems the students had, and how Emma's rejection of the group members' contributions entailed relational issues during the joint work:

224. Heini reconstructs the loop at another place on the roller coaster.

225. Emma: Quite small

226. Heini: Yes, we did a small one the last time we tried it

227. Emma: But it wasn't that small

228. Iida: Do you think it will have enough speed here?

229. Emma: No, but seriously, let's just challenge ourselves a little bit, because...

(Emma takes the loop in her hand and moves it back to where it originally was)

230. Heini: But there's this stupid joint (two pieces of foam rubber taped together)

231. Emma: I know! We'll tape it (Heini tries to say something, but Emma interrupts).

Heini, come on, just do the loop now.

232. Jenni: But I don't think the loop is very nice there

233. Emma: Jenni, do something yourself then if you have a better idea

234. Jenni: Yes, I'm doing. Let's - or you do the loop in another place

235. Heini: It would be better if this joint wasn't here

236. Emma: Yes, but there is no other place to put it

237. Emma (to Jenni): If you have a better idea, then you can comment

As noted above, Heini attempted to take the lead in the joint activity by exploring a new idea by reconstructing the loop at another place on the roller coaster in turn 224. In turn 225, Emma rejected Heini's leadership move in turn 224 by commenting on its size. In turn 229, Emma reinforced the rejection and made a leadership move with which she initiated exploring her original idea for the design of the roller coaster. In this same turn, she reinforced her leadership by making a simultaneous leadership move of coordinating joint work by gaining physical control over the materials. In turn 232, Jenni attempted to support Heini's initial leadership move in turn 224. In turn 233, Emma did not explicitly reject Jenni's argument, but the comment resulted in Jenni suggesting that Emma and Heini keep on reconstructing the loop. Emma again reinforced her role as a leader in the group work by determining the boundaries of Jenni's participation in turn 237. This excerpt illustrates how a dominant mode of leadership is constructed in the students' interaction: Emma was not willing to follow Heini's leadership move that involved exploring a new idea but forced the others to follow hers (turns 231 and 236), Jenni stepped back to let Heini and Emma work on the loop (turn 234), and Heini eventually constructed the loop where Emma suggested despite its problematic position (turn 235). The dominant mode of leadership resulted in difficulties in overcoming problems with the design of the roller coaster as well as entailed relational issues, such as quarrels, during the joint activity. 
Overall, the excerpts in this section illustrate how a dominant mode of leadership was constructed in the students' interaction. This interaction resulted in the group members' asymmetric opportunities to contribute to joint work, created tensions, such as quarrels among the students', and finally led to the students' inability to include multiple perspectives and ideas in the joint work. This dominant mode of leadership thus posed challenges during the collaborative design and making activity.

\section{Shared leadership}

We now move on to depict the interaction of another student group, consisting of Teemu, Kalle, Onni, and Elsa (Group 2). The students worked on the challenge called Laser Defender to design a maze for a laser beam to hit a target placed at the end of the maze. The materials kit included a laser pointer, small mirrors, a prism, and modeling clay.

In this group, all four students made leadership moves during the collaborative activity, and importantly, the leadership moves of individual students were evenly followed by the others (94.4\% of Teemu's leadership moves, $91.7 \%$ of Kalle's, and $80.0 \%$ of Onni's, see Table 3). That is, the students' leadership moves quite evenly resulted in a role of a legitimized leader, and thus all the students had opportunities to lead the joint work. This finding indicates that the students were making flexible shifts in leading and following. The only student who stood out in terms of being rejected was Elsa (see Table 3). However, compared with the other students, she made more leadership moves in which she took control over the materials. We also found that when the students rejected the leadership moves of the others, Teemu in particular initiated discussions about why the move was rejected, thus trying to promote the students' collaborative activity.

Across the group's work, the students appeared to make leadership moves flexibly and follow those of others, contributing to a mode of shared leadership within the group. In this group, Teemu made the most leadership moves $(40.4 \%)$ but seemed to take on a role of a tutor, which contributed to the shared mode of leadership. For instance, he frequently made leadership moves of exploring new ideas but let the other students have control over the materials and provided guidance and support in their use. In addition, he followed and built on new ideas of others. This more constructive mode of leadership enhanced the group's collaboration. The relations between the students were balanced, and the group completed two subsequent levels of the same challenge during the FUSE Studio session.

The following excerpt is a typical example of the leadership moves used by Teemu. Here, Teemu supported the others in exploring new ideas in joint work:

91. Teemu: Alright, there we have our target. I can (Teemu takes the laser pointer to his hand). Okay. Do you think that that (the mirror) should be that way around, or the other way? And where do you think we should start shooting the laser beam?

Table 3 Leadership moves in Group 2

\begin{tabular}{lllll}
\hline & Teemu & Kalle & Onni & Elsa \\
\hline $\begin{array}{l}\text { Leadership moves } \\
\begin{array}{l}\text { Leadership moves resulting in a role of leader } \\
\quad \text { (i.e., followed moves) }\end{array}\end{array}$ & $36(40.4 \%)$ & $12(13.5 \%)$ & $15(16.9 \%)$ & $26(29.2 \%)$ \\
$\begin{array}{l}\text { Leadership moves not resulting in a role of leader } \\
\quad \text { (i.e., followed moves) }\end{array}$ & $2(5.6 \%)$ & $1(8.3 \%)$ & $3(20.0 \%)$ & $10(38.5 \%)$ \\
\hline
\end{tabular}


This example illustrates how Teemu made a leadership move of coordinating joint work by taking the laser pointer after revising where the target is. In addition, he supported the other group members' participation in joint work by asking for their thoughts in relation to placing the materials. Teemu's leadership move thus promoted the students' symmetrical participation in the joint work.

Soon after, Teemu made a leadership move with which he proposed to explore a new idea in turn 118, which the students later took part in designing the laser maze quite symmetrically:

118. Teemu: Rotate it a little bit that way (Turns Elsa's hand, in which she is holding the laser pointer)

119. Elsa: It still hits Kalle's hand

120. Teemu: that way, that way, that way... (rotates the pointer)

121. Elsa: The beam is reflected over there

122. Onni: Wait! Teemu! (Onni moves a mirror on the course)

123. Elsa: It hits Onni's hand

124. Teemu: Alright. We need to put modeling clay under the pointer (Teemu begins to put modeling clay under the pointer, which Elsa is holding) So that it.. wait can I look at just one thing?

125. Elsa: Do you mean this? (Elsa keeps holding the pointer, picks up the modeling clay form under the pointer)

126. Teemu: You need to put it there underneath.

127. Elsa: Underneath this?

128. Teemu: Yeah, so that it sticks there. Why isn't the target there? Oh you (Kalle) have it, good.

129. Kalle: It (the laser beam) is on my hand

130. Elsa: No it's on your leg, now it's on your finger

131. Onni is holding a mirror and now moves towards the laser beam

132. Teemu: Now it hits it (the mirror), well done Onni!

133. Elsa: Target, target, target

134. Teemu: Now it bounces to... wait...

135. Kalle: It's there! in the trash can!

136. Onni attaches the target to the trash can

137. Kalle: put it a little bit higher

138. Teemu: it should be in the middle. Ok now it works.

This interactional episode illustrates how the students in this group had opportunities to lead joint work by making leadership moves. Specifically, Teemu, Onni, and Kalle take part in exploring new ideas in joint work: Teemu in turns 118 and 124 by suggesting to rotate the laser pointer and attaching the pointer to the floor with modeling clay, Onni in turns 122 and 131 by moving a mirror on the course, and Kalle in turn 137 by influencing how the target is placed on the course. Further, Teemu, Elsa, and Onni took part in coordinating joint work by taking tasks in the joint work: Teemu in turn 124 by taking the task of putting modeling clay under the pointer, Elsa in turns 125 and 133 by taking the task of adjusting the laser pointer and the modeling clay, and Onni in turn 136 by taking the task of attaching the target to the trash can. Overall, the shared mode of leadership is constructed in the students' interaction in which they flexibly made leadership moves and followed those of others. The students' leadership moves of exploring new ideas also built on each other, enhancing the students' collaboration. 
This next interactional episode depicts how Teemu offered guidance and support to other group members and how it contributed to the mode of shared leadership. Specifically, Teemu promoted the students' collaboration even when rejecting the other students' leadership moves. In this excerpt, Teemu rejected a leadership move by Onni but initiated a discussion on why he rejected the proposed idea:

213. Onni: This (the prism) goes...

214. Kalle: [interrupts] No

215. Onni: ...It goes right here

216. Teemu: Well, but then we need to get all of these into the one target that we have, so did you think about that?

217. Onni: No I didn't think of that... I didn't think all the way through to that

218. Teemu: Alright, well, we can put that (the prism) at the very end, next to the target, and the beam will bounce onto the target from there

In this example, Onni made a leadership move in which he proposed exploring a new idea by suggesting the placement of a prism in the maze (turn 213). Kalle rejected Onni's idea in turn 214 and so did Teemu in turn 216. Although Teemu rejected Onni's leadership move, he challenged Onni to think further into the task by explaining why he thought that Onni's proposal might not work. He recognized Onni's wish to include the prism in the structure, but in turn 218 , he suggested that they would do it later and suggested how it could be done. The students agreed, and continued to work by placing the mirrors in the structure first. In our view, the way that Teemu rejected Onni's solution not only advanced the development of the maze, but also balanced the relationships between members of the group.

Overall, although Teemu made the most leadership moves across this group's work (40.4\%), his guidance and support also promoted the other students in taking initiative and leadership in the group work. The shared mode of leadership was constructed in the students' interaction in which multiple perspectives and ideas were discussed and leadership was shared through flexible shifts in leading and following during the joint work. This mode of leadership thus had positive consequences for the students' collaboration.

\section{Discussion}

In this study, we have examined students' leadership moves and how leadership is related to students' collaboration in a school-based Makerspace. As a response to our first research question, we identified four types of leadership move that emerged from the students' group interaction in the makerspace: coordinating joint work, exploring new ideas, seeking out resources, and offering guidance and support to other group members. These results add to the existing literature on student leadership and collaboration in novel learning environments.

Our results show that coordinating joint work was the most common leadership move. It served an important role in the students' group interaction by providing structure to situations which involved various tools and materials. Coordination of joint work was evident in the interactions in which the students attended to the details of their creative work, managed and controlled the use of tools and materials, and followed the overall processes of their design and making activity (Table 1, rows 1-5). Our findings are consistent with previous research which 
has identified coordination as a pivotal part of collaboration (Li et al. 2007; Hennessy and Murphy 1999; Howe and Zachariou 2019; Sun et al. 2017).

In our data, leadership moves that explored new ideas entailed envisioning options in the design and creation of the artifacts. This became visible in the students' group interactions which included explorations to adjust or change the materials or designs of the artifacts to better fit the students' needs (Table 1, rows 6-8). Earlier studies on creative collaboration identified students' interaction around new ideas as important for the process of coconstructing knowledge and understanding and for creating new understandings and ways of thinking (Miell and Littleton 2004; Rojas-Drummond et al. 2008, 2014). Further, the literature has emphasized the role leadership plays in creating interactional spaces for envisioning how things could be (Shin et al. 2004). Our findings add to this understanding by illustrating how in a makerspace context, the students' use of hands-on materials when exploring new ideas can be of particular importance for affording opportunities for STEM-related knowledge construction (Table 1, row 7) and for creative engagement in design and making activities (Table 1, rows 6 \& 8) (see also Kumpulainen et al. 2019a; Dougherty 2016; Martin \& Dixon 2016; Peppler et al. 2016). Leadership moves that explore new ideas can hence play a particular role in open-ended and creative settings, such as in makerspaces (Certo 2011; Lee et al. 2005; Mawson 2011).

Our findings related to leadership moves which seek out resources demonstrate how the opportunity to navigate a variety of resources in the makerspace allows students to take leadership over their learning activities (see also Martin 2015; Peppler et al. 2016). This became visible in the interactions in which the students utilized the resources of the digital environment (Table 1, Row 9), sought help and assistance from their peers (Table 1, Row 11) and in some cases also from the teachers (Table 1, Row 10). Interactions which are evidence of seeking help from peers particularly exemplify how leadership in the makerspace environment allowed the students to act as models and mentors for each other in the design and making process (Peppler et al. 2016). These interactions are particularly important in makerspaces, and it has been suggested that makerspaces provide students with opportunities for relative expertise (Kumpulainen et al. 2019a; Dougherty 2016; Peppler et al. 2016) and transformative agency (Kajamaa and Kumpulainen 2019).

Our study identified leadership moves that involved the students offering guidance and support to each other, for example, by providing instructions to each other (Table 1, Row 12). Offering guidance and support also included the students helping each other in adjusting and changing the tools and materials (Table 1, Row 13) or modeling problem-solving problems for others (Table, Row 14). Such leadership moves echo earlier leadership research which has demonstrated that during collaboration, leadership can manifest itself as awareness of what others are doing, as sensing what they need, and as supporting others in taking part in joint work (Lee et al. 2005; Shin et al. 2004; McMahon and Goatley 1995). Moreover, supporting group members' work through dialog and action have previously been identified as important for collaboration (Hennessy and Murphy 1999; Howe and Zachariou 2019) and advancing equity and inclusivity of makerspaces (Giusti and Bombieri 2020). Overall, these findings resonate with the educational objectives of makerspaces (Dougherty 2013) in which relative expertise, enacted through supporting others by giving guidance and sharing knowledge, plays a crucial role (Marsh et al. 2019; Martin 2015; Wohlwend et al. 2017).

The results of our study also demonstrate how the students' leadership moves and their negotiation in group interactions were associated with qualitatively different forms of collaboration. Our findings revealed how a dominant mode of leadership was interactionally 
constructed in the students' work. Previous leadership research suggests that this kind of a dominant leadership mode may not help a group achieve its goals (Sun et al. 2017), as overpowering leadership can inflict tensions and conflicts between peers (Lee et al. 2005). This appeared clear in the first case highlighted in our article. In this group Emma was positioned as a single leader responsible for controlling the course of the activity, while Heini and Jenni had limited opportunities to contribute to exploring new ideas (Second excerpt, turns 224-237). Overall, in this group the students' interaction resulted in quarrels and inability to include multiple perspectives in the joint work, as Emma's explorations for new ideas overpowered those of others. Previous research suggests that students can have different trajectories for collaboration, some of them more self-focused, and these individual trajectories lead to differentially productive joint efforts (Barron 2003). Our findings add to this existing research by illustrating how these students' trajectories for collaboration and for leading joint work created asymmetrical opportunities to participate in joint design and making work. This in turn created obstacles for the co-construction of STEM-related knowledge (e.g., how to control the speed of the marble) during collaboration (see Miell and Littleton 2004; RojasDrummond et al. 2008) as well as for collaboration around the creative design of the artifact (see also Eteläpelto and Lahti 2008).

In the other group on which we focused in this study, a shared mode of leadership was constructed in the students' interaction. Within this group, the students considered each other's ideas (e.g., Teemu asking for the thoughts of the others in the first excerpt, turn 91). They also developed ideas together (third excerpt, turns 213-218) and alternated between the roles of leaders and followers during their collaboration (Second excerpt, turns 118-138). For example, the students' interactions around placing the prism (third excerpt 213-218) show how the shared mode of leadership promoted by Teemu's guidance and support created a space to envision how things could be (Shin et al. 2004) and promoted the other students in taking initiative and leader roles in the group work. This allowed the students to co-construct their understanding of the objectives of the design challenge as well as incorporate their knowledge creatively in the joint design of the laser maze. Overall, the shared mode of leadership promoted symmetric participation and co-construction of shared understanding, relevant for productive and creative collaboration (Rojas-Drummond et al. 2008, 2014; see also Authors 2019a; Dougherty 2016; Martin and Dixon 2016; Peppler et al. 2016).

\section{Conclusions}

We have made the case that an in-depth analysis of students' group interaction in a school-based makerspace allows for investigating their leadership moves and collaboration. In conclusion, our paper makes the following contributions. First, we have offered a typology of students' leadership moves in a novel, digitally enhanced makerspace environment. This typology highlights the ways in which the creative tasks and the use of various tools and materials as well as students' opportunities to build and use relative expertise create opportunities and requirements for students' leadership. Second, we provided new knowledge about how leadership is related to students' collaboration in such an open-ended and creative context. More specifically, we have added to the existing literature on students' collaboration by demonstrating how socially constructed modes of dominating and/or shared leadership led to less and more advanced forms of collaboration, respectively. The results illustrate how a dominant mode of leadership can result in students' asymmetric opportunities to participate in joint work and have consequences for how 
the students co-construct knowledge and collaborate on a creative task. In turn, a shared mode of leadership can promote symmetricity in students' participation and advance the co-construction of knowledge and creative collaboration.

Using leadership moves as an analytical unit gave us valuable information about how leadership has a contributory role in students' collaborative making and design work. Compared with more traditional and structured educational settings, makerspaces afford students with an opportunity to take more leadership over collaborative work by determining where the activity is focused and how the group work is conducted (Dixon and Martin 2014; Martin 2015; Peppler et al. 2016). Such student-directed aspects in makerspaces create new opportunities and tensions for students' leadership and collaboration (Ryoo and Kekelis 2018), as evidenced in the group cases presented in this study. Our findings call for developing pedagogical practices that promote students' symmetric participation, encourage students to consider multiple perspectives, and engage students in joint negotiation. As makerspaces are increasingly applied in formal education contexts, we pose the following questions for future research: How does students' leadership develop in different makerspaces? How is it connected with students' collaboration in situ and over time? Which pedagogical practices can best promote students' leadership in makerspaces?

There are limitations to this study that require careful consideration. The study was conducted in a FUSE Studio, a specific makerspace infrastructure, located within a school undergoing curriculum reform. The contextual features of both the makerspace and the school and its pedagogical practices could have influenced the ways the students took leadership over their design and making activities. In addition, the students were new to the FUSE Studio environment. It is possible that other types of leadership move could emerge once the students become accustomed to working in this learning environment. The number of student groups analyzed in this study was also rather small with consequences about the generalizability of our findings. Although we believe that other cases are likely to be characterized by analogous leadership moves, it would be important to examine cases in other makerspace settings and compare the findings, and to test our typology. Further, analyzing leadership proved to be challenging. The students rarely showcased leadership by explicitly stating that they will lead or let others lead joint work. We suggest that future research focuses on methodological development in tracking and analyzing students' leadership in makerspaces and other open-ended and creative learning environments. It can be considered that this study offers some direction to such research efforts.

Acknowledgments The research reported in this chapter was funded by the Academy of Finland Learning by Making: The educational potential of school-based makerspaces for young learners' digital competencies (iMake) project during the period of 2017-2020 (no: 310790); PI Kristiina Kumpulainen.

Funding Open access funding provided by University of Helsinki including Helsinki University Central Hospital. This research was financially supported by (text removed for the review process).

Data availability The authors do not have ethics approval to share the raw data from the current study as it consists of video data of children aged 9-12 years old.

\section{Compliance with ethical standards}

Conflict of interest The author(s) declared no potential conflicts of interest with respect to the research, authorship and/or publication of this article. 
Open Access This article is licensed under a Creative Commons Attribution 4.0 International License, which permits use, sharing, adaptation, distribution and reproduction in any medium or format, as long as you give appropriate credit to the original author(s) and the source, provide a link to the Creative Commons licence, and indicate if changes were made. The images or other third party material in this article are included in the article's Creative Commons licence, unless indicated otherwise in a credit line to the material. If material is not included in the article's Creative Commons licence and your intended use is not permitted by statutory regulation or exceeds the permitted use, you will need to obtain permission directly from the copyright holder. To view a copy of this licence, visit http://creativecommons.org/licenses/by/4.0/.

\section{References}

Barron, B. (2003). When smart groups fail. Journal of the Learning Sciences, 12(3), 307-359.

Brahms, L., \& Crowley, K. (2016). Making sense of making: Defining learning practices in MAKE magazine. In K. Peppler, E. R. Halverson, \& Y. B. Kafai (Eds.), Makeology-makers as learners (pp. 13-28). New York: Routledge.

Buchholz, B., Shively, K., Peppler, K., \& Wohlwend, K. (2014). Hands on, hands off: gendered access in crafting and electronics practices. Mind, Culture, and Activity, 21(4), 278-297.

Certo, J. (2011). Social skills and leadership abilities among children in small-group literature discussions. Journal of Research in Childhood Education, 25(1), 62-81.

Chemers, M. (2000). Leadership research and theory: A functional integration. Group Dynamics: Theory, Research, and Practice, 4(1), 27-43.

Christie, D., Tolmie, A., Thurston, A., Howe, C., \& Topping, K. (2009). Supporting group work in Scottish primary classrooms: Improving the quality of collaborative dialogue. Cambridge Journal of Education, 39(1), 141-156.

Dixon, C., \& Martin, L. (2014). Make to relate: Narratives of, and as, community practice. In J. L. Polman, E. A. Kyza, D. K. O’Neill, I. Tabak, W. R. Penuel, A. S. Jurow, K. O’Connor, T. Lee, \& L. D'Amico (Eds.), Proceedings of the international conference of the learning sciences (ICLS) 2014 (pp. 1591-1592). Boulder.

Dougherty, D. (2013). The maker mindset. In M. Honey \& D. E. Kanter (Eds.), Design. Make. Play. Growing the next generation of STEM innovators (pp. 7-16). New York: Routledge.

Dougherty, D. (2016). Foreword. In K. Peppler, E. R. Halverson, \& Y. B. Kafai (Eds.), Makeology Makerspaces as learning environments (pp. ix-xi). New York: Routledge.

Eteläpelto, A., \& Lahti, J. (2008). The resources and obstacles of creative collaboration in a long-term learning community. Thinking Skills and Creativity, 3(3), 226-240.

Giusti, T., \& Bombieri, L. (2020). Learning inclusion through makerspace: a curriculum approach in Italy to share powerful ideas in a meaningful context. The International Journal of Information and Learning Technology, 37(3), 73-86.

Gronn, P. (2000). Distributed properties: A new architecture for leadership. Educational Management Administration Leadership, 28(3), 317-338.

Hennessy, S., \& Murphy, P. (1999). The potential for collaborative problem solving in design and technology. International Journal of Technology and Design Education, 9(1), 1-36.

Howe, C., \& Zachariou, A. (2019). Small-group collaboration and individual knowledge acquisition: The processes of growth during adolescence and early adulthood. Learning and Instruction, 60, $263-274$.

Jordan, B., \& Henderson, A. (1995). Interaction analysis: foundations and practice. Journal of the Learning Sciences, 4(1), 39-103.

Kajamaa, A. \& Kumpulainen, K. (2019). Agency in the making: Analyzing students' transformative agency in a school-based makerspace. Mind, Culture, and Activity, 26(3), 266-281.

Kantor, R., Elgas, P., \& Fernie, D. (1993). Cultural knowledge and social competence within a preschool peer culture group. Early Childhood Research Quarterly, 8(2), 125-147.

Kumpulainen K., Kajamaa A., Rajala A. (2019) Motive-Demand Dynamics Creating a Social Context for Students' Learning Experiences in a Making and Design Environment. In A. Edwards, M. Fleer, L. Bøttcher (eds) Cultural-Historical Approaches to Studying Learning and Development. Perspectives in Cultural-Historical Research, vol 6 (pp. 185-199). Singapore: Springer

Lee, S. Y., Recchia, S., \& Shin, M. S. (2005). "Not the same kind of leaders": Four young children's unique ways of influencing others. Journal of Research in Childhood Education, 20(2), 132-148.

Li, Y., Anderson, R., Nguyen, K., Dong, T., Archodidou, A., Kim, I. -H., \& Kuo, L. - J., Clark, A., Wu, X., Jadallah, M., \& Miller, B. (2007). Emergent leadership in children's discussion groups. Cognition and Instruction, 25(1), 75-111. 
Marsh, J., Wood, E., Chesworth, L., Nisha, B., Nutbrown, B., \& Olney, B. (2019). Makerspaces in early childhood education: principles of pedagogy and practice. Mind, Culture, and Activity, 26(3), 221-233.

Martin, L. (2015). The promise of the maker movement for education. Journal of Pre-College Engineering Education Research, 5(1), 30-39.

Martin, L., \& Dixon, C. (2016). Making as a pathway to engineering and design. In K. Peppler, E. R. Halverson, \& Y. B. Kafai (Eds.), Makeology - makers as learners (pp. 13-28). New York: Routledge.

Mawson, B. (2011). Children's leadership strategies in early childhood. Journal of Research in Childhood Education, 25(4), 327-338.

McMahon, S., \& Goatley, V. J. (1995). Fifth graders helping peers discuss texts in student-led groups. The Journal of Educational Research, 89(1), 23-34.

Mercier, E. M., Higgins, S. E., \& da Costa, L. (2014). Different leaders: emergent organizational and intellectual leadership in children's collaborative learning groups. International Journal of Computer-Supported Collaborative Learning, 9(4), 397-432.

Miell, D., \& Littleton, K. (2004). Collaborative creativity. Contemporary perspectives. London: Free Association Books.

Miller, B., Sun, J., Wu, X., Anderson, R.C (2013). Child leaders in collaborative groups. In C. Hmelo-Silver, C.A. Chinn, C.K.K. Chan \& A. O'Donnell (Eds.), The international handbook of collaborative learning (pp. 268-280). New York: Routledge.

Mullarkey, L., Recchia, S., Lee, S., Shin, M., \& Lee, Y. (2005). Manipulative managers and devilish dictators: teachers' perspectives on the dilemmas and challenges of classroom leadership. Journal of Early Childhood Teacher Education, 25(2), 123-129.

Peppler, K., Halverson, E. R., \& Kafai, Y. B. (2016). Introduction. In K. Peppler, E. R. Halverson, \& Y. B. Kafai (Eds.), Makeology - Makerspaces as learning environments (pp. 1-11). New York: Routledge.

Richmond, G., \& Stirley, J. (1996). Making meaning in classrooms: social processes in small-group discourse and scientific knowledge building. Journal of Research in Science Teaching, 33(8), 839-858.

Rojas-Drummond, S. M., Albarrán, C. D., \& Littleton, K. S. (2008). Collaboration, creativity and the coconstruction of oral and written texts. Thinking Skills and Creativity, 3(3), 177-191.

Rojas-Drummond, S. M., Mazón, N., Littleton, K., \& Vélez, M. (2014). Developing reading comprehension through collaborative learning. Journal of Research in Reading, 37(2), 138-158.

Ryoo, J., \& Kekelis, L. (2018). Reframing "failure" in making: The value of play, social relationships, and ownership. Journal of Youth Development, 13(4), 49-67.

Shin, M. S., Recchia, S. L., Lee, S. Y., Lee, Y. J., \& Mullarkey, L. S. (2004). Understanding early childhood leadership: emerging competencies in the context of relationships. Journal of Early Childhood Research, 2(3), 301-316.

Siewiorek, A., Saarinen, E., Lainema, T., \& Lehtinen, E. (2012). Learning leadership skills in a simulated business environment. Computers \& Education, 58(2012), 121-135.

Srivastava, P., \& Hopwood, N. (2009). A practical iterative framework for qualitative data analysis. International Journal of Qualitative Methods, 8(1), 76-84.

Stevens, R. \& Jona, K. (2017). Program design. FUSE studio website. https://www.fusestudio.net/programdesign. Accessed June 6 June 2019.

Stevens, R., Jona, K., Penney, L., Champion, D., Ramey, K. E., Hilppö, J., Echevarria, R., \& Penuel, W. (2016). FUSE: An alternative infrastructure for empowering learners in schools. In Proceedings of International Conference of the Learning Sciences, ICLS, 2(2016) (pp. 1025-1032).

Sun, J., Anderson, R.C, Perry, M., Lin, T-J. (2017). Emergent leadership in Children's cooperative problem solving groups. Cognition and Instruction, 35(3), 212-235.

Timmermans, S., \& Tavory, I. (2012). Theory construction in qualitative research: from grounded theory to abductive analysis. Sociological Theory, 30(3), 167-186.

Volet, S., Vauras, M., Salo, A.-E., \& Khosa, D. (2017). Individual contributions in student-led collaborative learning: insights from two analytical approaches to explain the quality of group outcomes. Learning and Individual Differences, 53, 79-92.

Wohlwend, K. E., Peppler, K. A., Keune, A., \& Thompson, N. (2017). Making sense and nonsense: comparing mediated discourse and agential realist approaches to materiality in a preschool makerspace. Journal of Early Childhood Literacy, 17(3), 444-462.

Yamaguchi, R. (2001). Children's learning groups: a study of emergent leadership, dominance, and group effectiveness. Small Group Research, 32(6), 671-669. 
Jasmiina Leskinen (MA in Education), is a doctoral researcher at the Faculty if Educational, Sciences, University of Helsinki, Finland. For her doctoral research, she has conducted video-based research, informed by cultural-historical theories of learning and education.

\section{Current themes of research:}

Her current research focuses on elementary school students' socially constructed leadership in a school-based makerspace.

Kristiina Kumpulainen is Professor of Education and Scientific Director of the Playful Learning Center at the Faculty of Educational Sciences, University of Helsinki, Finland. She also co-chairs Learning, Culture and Interventions (LECI) research expert group of her faculty. She has led numerous research projects and published widely on socioculturally informed studies on children's agency and learning across early years and primary education, cultural institutions, and homes.

\section{Current themes of research:}

Her research has addressed pedagogies and learning environments that create opportunities for creative, dialogic, and participatory learning. Her ongoing research projects include The Joy of Learning Multiliteracies funded by the Finnish Ministry of Education and Culture, Learning by Making: The Educational Potential of School-based Makerspaces for Young Learners' Digital Competencies funded by the Academy of Finland, and Digital Mediation of Children's Interactions with the More-than-human World: Perezhivaniya and Literate Practicesfunded by the Australian Research Council (ARC).

At present, she chairs the Nordic Research Network on Digitalising Childhoods funded by the NOS HS program of the Academy of Finland.

Most relevant publications in the field of Psychology of Education:

For publications see: https://tuhat.helsinki.fi/portal/fi/person/krkumpul

Anu Kajamaa is an Associate Professor and is co-leader of the Learning, Culture and Interventions (LECI) research community with Professor Kristiina Kumpulainen at the Faculty of Educational Sciences, University of Helsinki, Finland. She has conducted collaborative research and intervention projects in schools, teacher education, health care, and entrepreneurship contexts and published in international journals.

Current themes of research:

Her current research focuses on children's learning, development, and creativity in school-based makerspaces.

Most relevant publications in the field of Psychology of Education:

Kajamaa, A., Kumpulainen, K. \& Rajala, A. (2018). Digital learning environment mediating students' funds of knowledge and knowledge creation. Studia Paedagogica 23, 4.

Kumpulainen, K., Kajamaa, A. \& Rajala, A. (2018). Understanding educational change: Agency-structure dynamics in a novel design and making environment. Digital Education Review 33, 26-38.

Kumpulainen, P. K., Kajamaa, A. M. \& Rajala, A. (2019). Motive-demand dynamics creating a social context for students' learning experiences in a making and design environment. Cultural-historical approaches to studying learning and development: societal, institutional and personal perspectives. Edwards, A., Fleer, M. \& Bottcher, L. (Eds.). SAGE Publications Ltd. (minulla ei ole kirjaa tässä, sorry kun en voi tarkistaa sivunumeroita).

Kajamaa, A., Kumpulainen, K. \& Olkinuora, H-R. (in press). Teacher interventions in students' collaborative work in a technology-rich educational makerspace. British Journal of Educational Technology. 
Kajamaa, A. \& Kumpulainen, K. (in press). Agency in the Making: Analyzing students' transformative agency in a school-based makerspace. Mind, Culture and Activity.

Kajamaa, A., Kumpulainen, K. (In press). Special issue "Young people, digital mediation and transformative agency" forMind, Culture and Activity.

Antti Rajala, $\mathrm{PhD}$, is a postdoctoral researcher at the Faculty of Educational Sciences, University of Helsinki. Rajala has conducted video-based and ethnographic research in schools on the topics of dialogic pedagogy, educational change, and agency. His work has been informed by dialogical and cultural-historical theories of learning and education.

Current themes of research:

His current research focuses on compassion in education as well as global education. Rajala is one of the editors in Outlines: Critical Practice Studies and belongs to the editorial board of Dialogic Pedagogy: An International Online Journal. He is also the Book Reviews Editor of the Mind Culture and Activity journal.

Most relevant publications in the field of Psychology of Education:

Rajala, A. (2019). Expanding the context of school learning to the surrounding communities: A sketch for a pedagogy. Psychology and Society, 11(1), 161-175.

Rajala, A., Kumpulainen, K., Rainio, A. P., Hilppö, J., \& Lipponen, L. (2016). Dealing with the contradiction of agency and control during dialogic teaching. Learning, Culture and Social Interaction, 10, 17-26.

Rajala, A., \& Akkerman, S. (2019). Researching reinterpretations of educational activity in dialogic interactions during a fieldtrip. Learning, Culture and Social Interaction, 20, 32-44.

Publisher's note Springer Nature remains neutral with regard to jurisdictional claims in published maps and institutional affiliations. 